\title{
Why resident physicians stay late
}

$\mathrm{T}$ hose who believe service is an essential component of training offer examples: staying late to see a new consult, revising a dictation, documenting the medications used in a code. ${ }^{1}$ But these activities are luxuries. Here is why residents really stay late.

A few years ago, as I put on my coat ...

— Dr. P, are you leaving?

- Yes.

— Just one thing.

- Sure.

- Mr. Robinson in 1902, I think he's in his 70s. He has a cream you need to order. He forgot to tell you.

- What is it?

- I don't know. He puts it on his nose. Hold on, let me get it.

My mind turns to Mr. Robinson. What medications he is on; why he is here? Five minutes pass.

- Here it is.

- Erythromycin 2\% gel. Must be for his rosacea. He wants to keep using this? (The data is lacking. ${ }^{2}$ )

- Yes.

- Ok. (I know to pick my battles.)

— Great, can you order it?

- Can't we just use this? (It's a full tube.)

- Yeah, but we need an order so he can use it.

I shake the mouse. Please enter your Windows password. LOADING. The desktop appears. I double-click the electronic medical record (EMR). LOADING. The login screen appears. I enter my username and password. Computer parts grind audibly. The EMR opens.

I type in "ERYTHROMYC." Options appear: erythromycin delayedrelease tablet, erythromycin ethyl succinate oral suspension, erythromycin lactobionate infusion, erythromycin ophthalmic ointment, but no gel or cream. A few more tries convinces me it is not under any derivation of erythro.

So, I decide to order it as a miscellaneous medication. "MISC." No results. "Medicatio ...". No results. "Non formulary ...". No results. I search for the nurse.

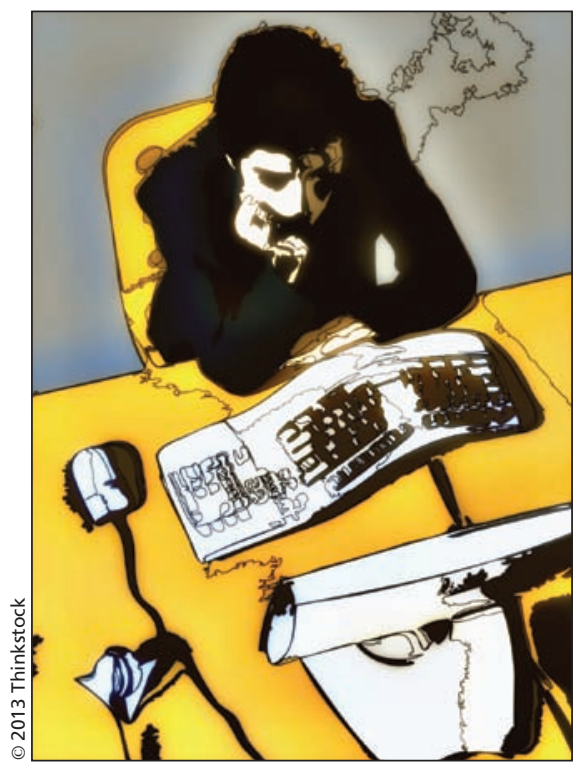

- Do you know how to order this gel? It's not in the formulary.

- You have to call pharmacy.

I call pharmacy.

- The order is under non-formulary.

- I'm typing non-formulary.

- Did you put a dash? It's non DASH formulary.

At last it appears. Non-formulary request. So I fill in the fields. The order is placed.

Not much has changed over the past 20 years. Most of the time an intern is on call $(40 \%)$ is spent buffing an electronic medical record (EMR). ${ }^{3}$ Similar surveys from the early 1990s showed that $44 \%$ of time was spent performing administrative tasks. These data provide a sobering picture of training, but don't fully capture the absurdity of the job.

Recently, I was asked if a patient could use lip balm for his dry lips. "Of course," I replied without hesitation.

I'm going to need an order for that.

An order for lip balm? If I walked up to one of the hospital's computers, logged onto Windows, and then the EMR, and then located the patient's chart, opened the orders tab, found and placed the order, and then re-entered my password to sign it - that would take three minutes. If instead, I wrote it down, and entered it the next time I was in the patient's chart, the lip balm would be delayed and I would have to remember to order it in the future. I would have to keep track of lip balm, along with doses of Lasix, when to hold anticoagulation and a host of medical matters.

If the lesson here is, good doctors must be detail-oriented, don't I learn that from the 26 orders I place each day? Do I need a 27th order to learn meticulousness? More likely, lip balm orders are a draconian measure implemented to save a buck from disappearing lip balm tubes. I won't be surprised if in a few more years lip balm will need to be cosigned by the attending.

- Doctor, can I take out his PICC line? - Yes.

— I'm going to need an order for that.

- This is the order. Right now, this conversation. This is a verbal order.

- Oh, that won't do.

If we want to make an honest appraisal of "service," we have to be honest about what it entails: the banal, tedious, time-consuming tasks of buffing a poorly designed EMR just to get a nurse or pharmacist to stop calling you.

\section{Vinay Prasad MD}

Medical Oncology Branch, Fellow

National Cancer Institute

National Institute of Health

Bethesda, Md.

The views and opinions of the author do not necessarily reflect the organizations with which he is associated. Mr. Robinson is a composite of several patients over time; some of the details of his case have been altered, but none of the frustration.

\section{References}

1. Kesselheim JC, Cassel CK. Service: an essential component of graduate medical education. $N$ Engl J Med 2013;368:500-1

2. Mills OH Jr, Kligman AM. Letter: topically applied erythromycin in rosacea. Arch Dermatol 1976;112:553-4

3. Fletcher KE, Visotcky AM, Slagle JM, et al. The composition of intern work while on call. $J$ Gen Intern Med 2012;27:1432-7.

CMAJ 2013. DOI:10.1503/cmaj.130528

All editorial matter in CMAJ represents the opinions of the authors and not necessarily those of the Canadian Medical Association. 